\title{
Energy efficient process of nitrification and denitrification in activated sludge system with low organic load
}

\author{
I.A.Gulshin ${ }^{1, *}$ and E.S Gogina ${ }^{1}$ \\ ${ }^{1}$ Moscow State University of Civil Engineering, 129337, Moscow, Yaroslavskoye shosse, 26, Russia
}

\begin{abstract}
The article summarizes the results of the second phase of a comprehensive study of energy efficient wastewater treatment processes in oxidation ditches. Dependence of the efficiency of simultaneous nitrification and denitrification at the change of oxygen regime have been determined at the second phase of the study. Results of the phase confirm the fundamental possibility of the withdrawal of biomass in energyefficient mode with high quality of wastewater treatment.
\end{abstract}

\section{Introduction}

Biochemical and physical modelling of wastewater treatment is an important practice for the design and operation of wastewater treatment plants. Process errors identified during the modelling can significantly reduce the financial and environmental risks [1].

Complex investigations, which include both mathematical modelling and laboratory experiments, take place at the Moscow State University of Civil Engineering (NRU MSUCE) $[2,3,4]$.

The base process in these studies is Simultaneous Nitrification and Denitrification (SND) and the key experimental construction is oxidation ditch. Simultaneous nitrification and denitrification - is one of the most economical methods for nitrogen removal. Both biochemical reactions (nitrification and denitrification) occur concurrently under identical operating conditions in the same reactor without separation into aerobic and anoxic macrozones in this process. The aim of a physical experiment as part of a comprehensive study is to obtain and update the main control values required for further modelling and design of WWTP.

The physical explanation is that the SND occurs because of concentration gradients within the floc due to diffusion limitations [5, 6]. Flocs have a large size, anaerobic center and aerobic outer layers $[7,8]$. They are formed under the influence of specific hydraulic and oxygen regimes. The structure of outer layers affects the dissolved oxygen diffusion coefficients and increases the efficiency of nitrification in low-oxygen conditions in the bioreactor [9].

*Corresponding author: GulshinIA@mgsu.ru 
Based on preliminary investigations it was found that the most promising structures for the implementation of the technology of simultaneous nitrification and denitrification are oxidation ditches [10].

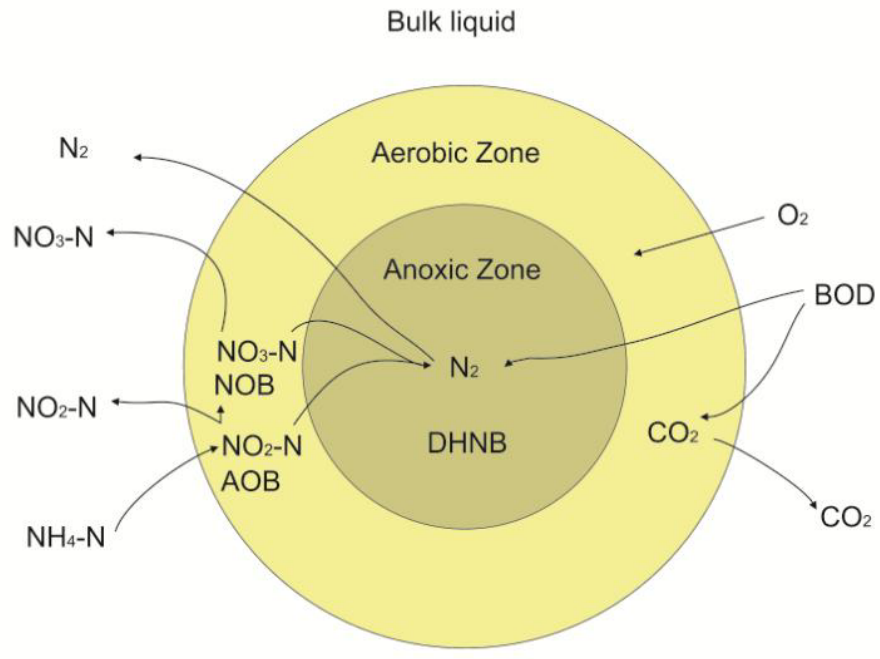

Fig. 1. Diagram of SND in an activated sludge floc.

In addition to the physical explanation of simultaneous nitrification and denitrification, there are a number of theories of microbiological character. For example, it has been suggested that some of the denitrifying microorganisms involved in of simultaneous nitrification and denitrification are autotrophic $[11,12]$. This means that the need for a readily oxidized carbon source for denitrification effectively reduced in the process. This is quite important because of the low-carbon wastewater, common to most regions of the Russian Federation.

\section{Methodology \& research}

The aim of a physical experiment as part of a comprehensive study is to obtain and update the main control values that are required for further modelling and design of WWTPs. The NRU MSUCE has extensive experience in creation and operation of laboratory models of bioreactors, which allow recreating the conditions of the experiment.

Two different models of oxidation ditches are currently created as a part of this study.

The first type of bioreactor is a model with a vertical flow of the circulating fluid, consisting of two consecutive modules. This model eliminates stagnant zones and provides the best conditions for biomass research work. This raises difficulties hydraulic regulating pattern mode, in particular, a greater part of the reactor cannot create a stable laminar flow of liquid. In addition, the experiment in this model does not account for the precipitation of active sludge at various flow rates. 

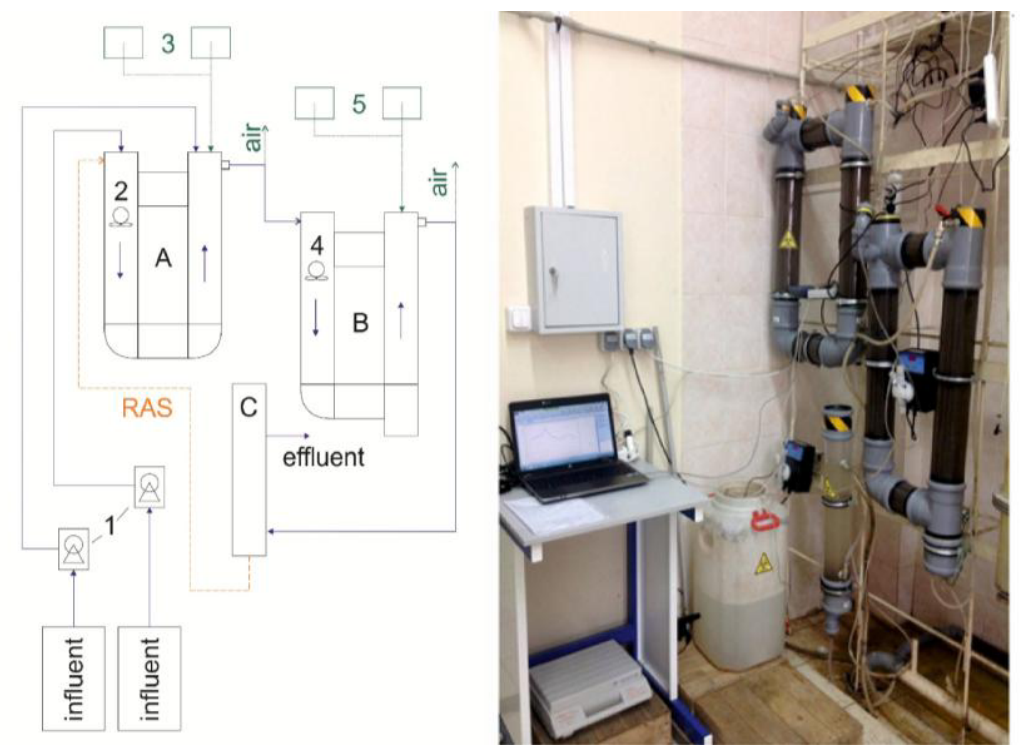

Fig. 2. Lab-scale oxidation ditch with vertical flow. A - zone 1, B - zone 2, C - secondary settler; 1 metering pumps, 2, 4 - mechanical stirrers, 3 - low-intensity blowers, 5 - blowers.

The first two phases of the experiment were carried out using this model. The total volume of the bioreactor consisting of two modules was 35 liters. The volume of the secondary settler was 4 liters. The daily flow of wastewater was 115 liters with the fractional pitch; the average hydraulic retention time was 7.5 hours.

The second type of bioreactor is a model with a horizontal flow of the circulating fluid. The laboratory setup consists of experimental and control lines. The control line models the standard operation mode of the existing oxidation ditches. It is possible to create uniform aeration regimes with high levels of dissolved oxygen in water and common denitrinitrification schemes. The experimental line is designed to create the most favorable conditions for the simultaneous nitrification and denitrification and evaluate its work. The working volume of each line is 35 liters, which allows correlating the results with the experimental stages formed on the same vertical type volume model. Each line is equipped with its own secondary clarifier and feed pump, which makes them completely independent of each other.

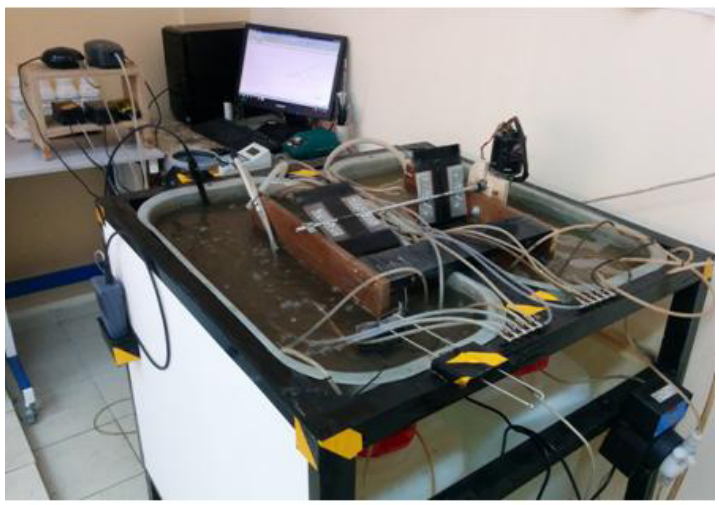

Fig. 3. Lab-scale oxidation ditch with horizontal flow. 
An automated mixer, rotating at minimum speed (less than $1 \mathrm{tpm}$ ), achieves fluid flow in the experimental line. Minimum speed of rotation and the special shape of the blades help to avoid additional oxygen saturation due to intense mechanical action. Automatic aeration system allows to avoid stagnant zones which had collapsed activated sludge, thereby avoiding excessive saturation of water with oxygen.

As the study is directed primarily to study the properties of the working biomass in the experimental conditions of operation, it is necessary accurately to pick up the substrate, used in a laboratory simulation as treated wastewater. During the experiment, the substrate is made with the relevant characteristics close to the characteristics of the actual wastewater Moscow region.

Control of the experimental models is carried out by automated sensors of dissolved oxygen and redox potential. Chemical analyzes of water from certain control points are performed on modern analytical equipment for certified procedures.

\section{Results}

Now there is a third phase of laboratory experiment. The results and conclusions of the first phase were presented earlier. Based on these results it has been adjusted "work plan" for the second phase of the experiment. The second phase of the experiment took 5 months. Activated sludge for inoculation was delivered from the existing wastewater treatment plant. Originally, an experimental system has been launched on well-aerated nitrifying activated sludge, before does not need to adapt to low-DO operating conditions. The adaptation mechanism of the activated sludge to the low-DO conditions have been described earlier.

Table 1. Results of the experiment with vertical-flow lab-scale OD.

\begin{tabular}{|c|c|c|c|c|c|c|c|c|c|}
\hline $\begin{array}{l}\text { Days of } \\
\text { experi- } \\
\text { ment }\end{array}$ & $\begin{array}{l}\text { Control } \\
\text { points }\end{array}$ & $\begin{array}{l}\text { Average } \\
\text { DO, mg/L }\end{array}$ & $\begin{array}{l}\text { MLSS, } \\
\text { g/1 }\end{array}$ & $\begin{array}{l}\mathrm{COD}, \\
\mathrm{mgO} / 1\end{array}$ & $\begin{array}{l}\mathrm{BOD}_{5}, \\
\mathrm{mgO}_{2} / 1\end{array}$ & $\begin{array}{l}\mathrm{NH}_{4}, \\
\mathrm{mg} / \mathrm{l}\end{array}$ & $\begin{array}{l}\mathrm{NO}_{2}, \\
\mathrm{mg} / \mathrm{l}\end{array}$ & $\begin{array}{l}\mathrm{NO}_{3}, \\
\mathrm{mg} / 1\end{array}$ & $\begin{array}{l}\mathrm{PO}_{4}, \\
\mathrm{mg} / \mathrm{l}\end{array}$ \\
\hline $1-35$ & $\begin{array}{l}\text { influent } \\
\text { effluent }\end{array}$ & 0,8 & 2,025 & $\begin{array}{c}145,7 \\
10,4\end{array}$ & $\begin{array}{l}124 \\
5,7\end{array}$ & $\begin{array}{l}39,76 \\
10,05\end{array}$ & $\overline{-}$ & $\begin{array}{c}- \\
69,3\end{array}$ & $\begin{array}{l}15,0 \\
12,5\end{array}$ \\
\hline $36-82$ & $\begin{array}{l}\text { influent } \\
\text { effluent }\end{array}$ & 0,6 & 2,189 & $\begin{array}{c}141,1 \\
6,1\end{array}$ & $\begin{array}{l}122 \\
2,6\end{array}$ & $\begin{array}{c}41,72 \\
0,94\end{array}$ & $\overline{-}$ & $\begin{array}{c}- \\
43,8\end{array}$ & $\begin{array}{c}15,4 \\
9,9\end{array}$ \\
\hline $83-115$ & $\begin{array}{l}\text { influent } \\
\text { effluent }\end{array}$ & 0,3 & 1,578 & $\begin{array}{c}127,6 \\
21,2\end{array}$ & $\begin{array}{l}110 \\
9,9\end{array}$ & $\begin{array}{l}42,35 \\
15,48\end{array}$ & $\begin{array}{c}- \\
2,11\end{array}$ & $\begin{array}{c}- \\
25,1\end{array}$ & $\begin{array}{l}15,5 \\
11,2\end{array}$ \\
\hline 116-181 & $\begin{array}{l}\text { influent } \\
\text { effluent }\end{array}$ & 0,5 & 2,436 & $\begin{array}{c}140,5 \\
5,2\end{array}$ & $\begin{array}{l}121 \\
2,2\end{array}$ & $\begin{array}{c}42,87 \\
0,84\end{array}$ & $\begin{array}{c}- \\
0,15\end{array}$ & $\begin{array}{c}- \\
38,5\end{array}$ & $\begin{array}{c}15,1 \\
8,7\end{array}$ \\
\hline
\end{tabular}

The first period, which took 35 days, included biomass adaptation to the new substrate and oxygen conditions and the withdrawal of installations in operation. Since during adaptation of the activated sludge, wastewater treatment processes are unstable chemical analysis results for the time not included in subsequent calculations.

Calculations are shown below. 


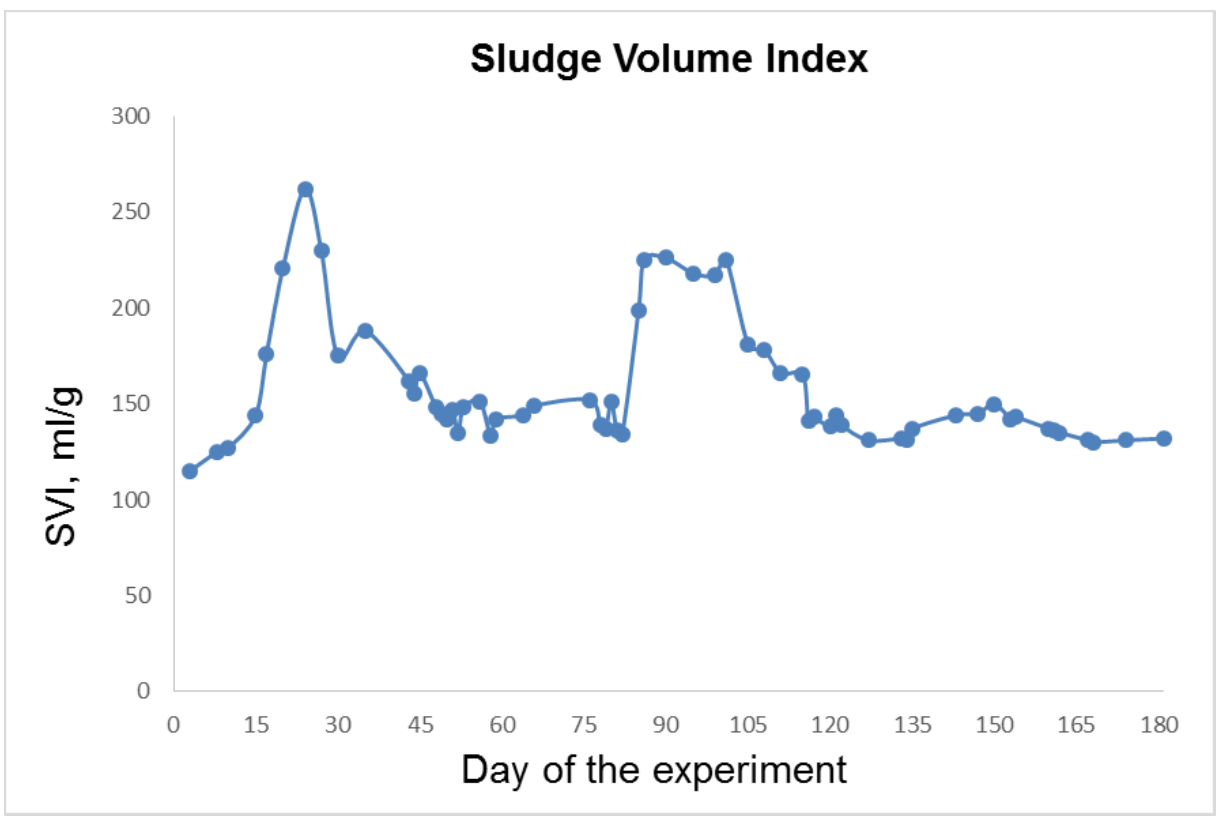

Fig. 4. Changing the sludge volume index in time.

After the adaptation of the activated sludge, process of simultaneous nitrification and denitrification was quite stable. Operation in this mode for about two months, showed good results. After two months of stable operation with the level of dissolved oxygen $0.6 \mathrm{mg} / \mathrm{l}$, it was decided to reduce its concentration to $0.15-0.2 \mathrm{mg} / \mathrm{l}$. During this period the substrate flow was decreased and, accordingly, organic load on the biomass. Expectedly happened filamentous bulking of the activated sludge. System's stability recovery process was launched. System recovery to an acceptable sludge volume index took about two weeks, after which it was again set to work with the simultaneous nitrification and denitrification. The removal of nitrogen is gradually increased with increasing sludge age and the formation of large flocs.

By the Lineweaver-Burk Plot for the oxidation rate of organic matter the equation was built and a Michaelis-Menten constant (1) and maximum rate of the reaction (2) were calculated:

$$
\begin{gathered}
\mathrm{K}_{\mathrm{m}}=3,38 \\
\mathrm{~V}_{\max }=24,21 \mathrm{mgBOD} /(\mathrm{g} \cdot \mathrm{h}) \\
\mathrm{V}=\left(\mathrm{V}_{\max } S\right) \cdot\left(\mathrm{K}_{\mathrm{m}}+S\right)^{-1}=(24,21 S) \cdot(3,38+S)^{-1}
\end{gathered}
$$

At the same time, as noted above, in the preparation of dependence is not taken into account periods of the initial adaptation of biomass (red markers) and recovery from a filamentous bulking (yellow markers). 


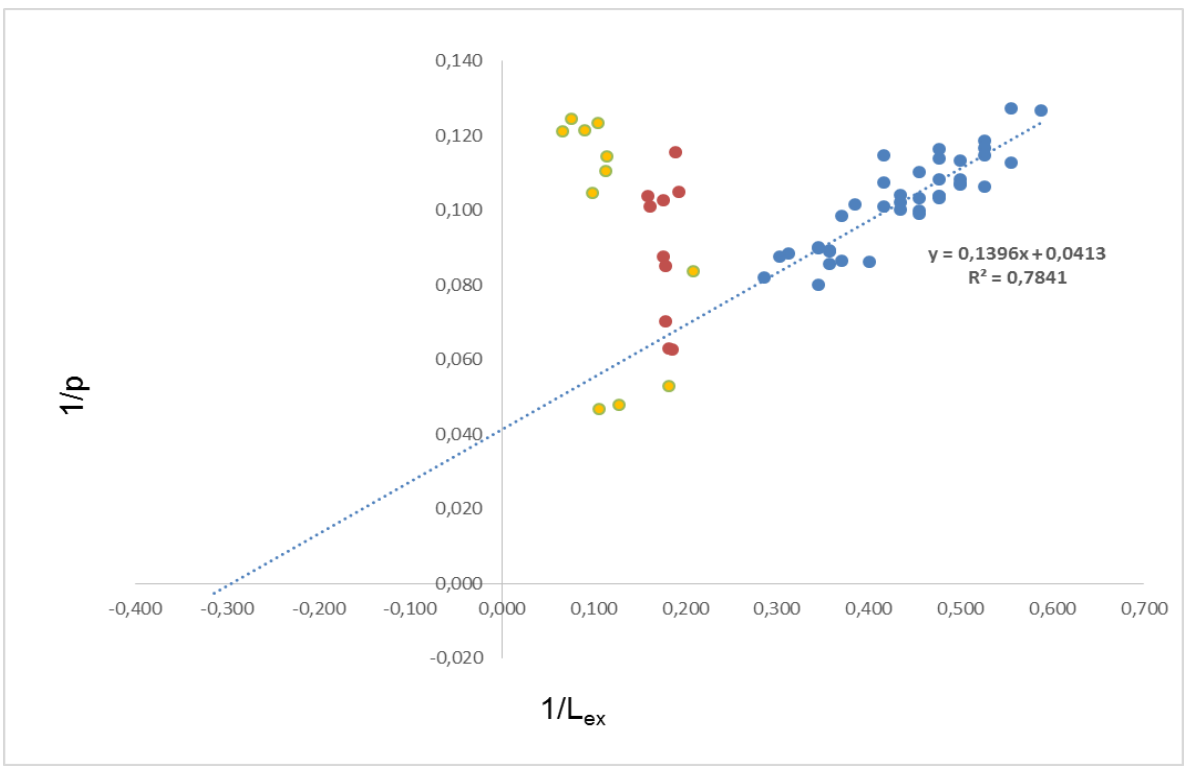

Fig. 5. Lineweaver-Burk Plot for the oxidation rate of organic matter.

Lineweaver-Burk Plot for nitrification rate allowed to determine the value of a Michaelis-Menten constant (4) and maximum rate of the reaction (5):

$$
\begin{gathered}
\mathrm{K}_{\mathrm{mN}}=0,106 \\
\mathrm{~V}_{\operatorname{maxN}}=4,69 \mathrm{mgNH}_{4} /(\mathrm{g} \cdot \mathrm{h}) \\
\mathrm{V}=\left(\mathrm{V}_{\operatorname{maxN}} S\right) \cdot\left(\mathrm{K}_{\mathrm{mN}}+S\right)^{-1}=(4,69 S) \cdot(0,106+S)^{-1}
\end{gathered}
$$

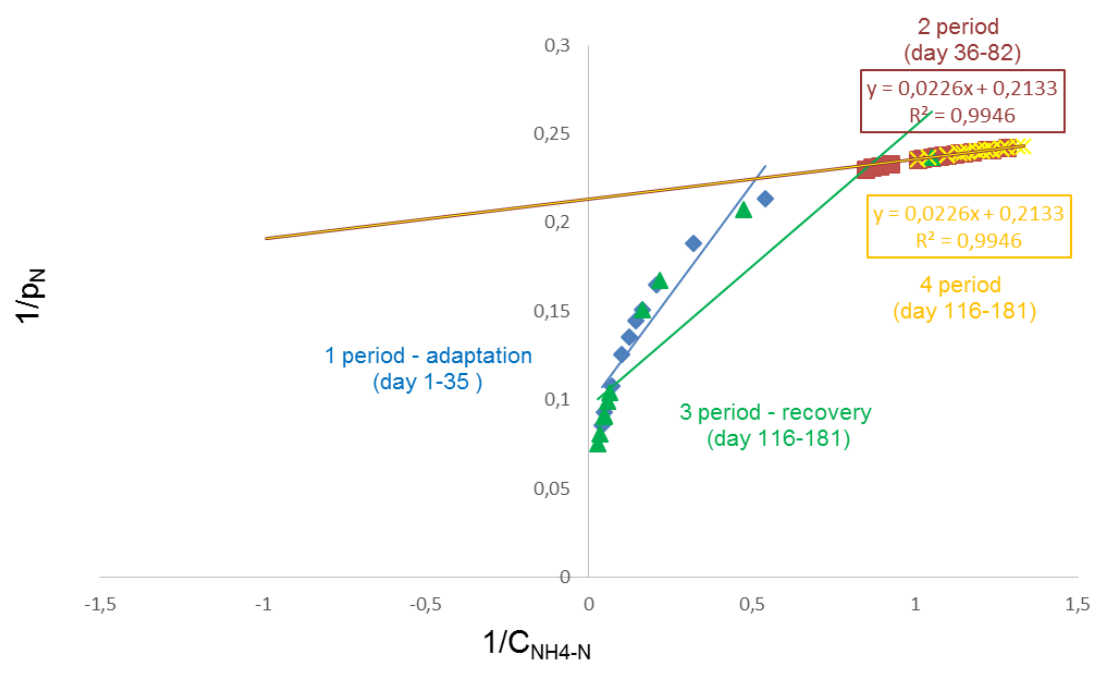

Fig. 6. Lineweaver-Burk Plot for the nitrification rate. 
It should be noted that the dependence of the second and fourth periods coincided, showing a sufficiently high value authenticity of the linear approximation. Periods of adaptation and recovery of activated sludge is not involved in the drafting of dependence, due to the high volatility of the process. Although the accuracy of the linear approximation of these values as high enough. Phosphorus removal stably kept at a level that corresponds to the removal of phosphates with the oxidation of organic matter by heterotrophic organisms. For deep biological phosphorus removal, it is necessary to create more pronounced anaerobic zones in the activated sludge floc centers.

\section{Conclusions}

The process of simultaneous nitrification and denitrification, undoubtedly shows the high efficiency at the lowest operating costs for aeration. Potential negative factors: non-uniform composition of the organic substrate, inhibitors in the influent, problems with hydraulic flow and the occurrence of stagnant zones. Features of original adaptation mechanism of activated sludge to the conditions of low dissolved oxygen concentration in the bioreactor allows to create in the future a stable system that can quickly recover from disruptions.

For further investigate the prospects of the use of the technology it is necessary to carry out additional tests, taking into account the hydraulic flows and the need to maintain the biomass in suspension while maintaining a reduced intensity of aeration, as well as studies on the real wastewater.

\section{References}

1. N. Lesage, M. Spe'randio, C. Lafforgue, A. Cockx, Trans IChemE, Part A, 81, 1259 (2003)

2. E. Gogina, I. Gulshin, Procedia Engineering, 117, 107 (2015)

3. N. Makisha, E. Gogina, Applied Mechanics and Materials, 587-589, 644-647 (2014)

4. E. Gogina, I. Gulshin, Procedia Engineering, 153, 189-194 (2016)

5. E. Pittoors, Y. Guo, S. W. H. V. Hulle, Chem. Eng. Comm., 201, 983-1002 (2014)

6. J. Jimenez, C. Bott, P. Regmi, L. Rieger, Proceedings of the Water Environment Federation, 4, 492-505 (2013)

7. G. Zhu, Y. Peng, S. Wu, S. Wang, S. Xu, Journal of Environmental Sciences, 19, 1043-1048 (2007)

8. Y. Liu, H. Shi, L. Xia, H. Shi, T. Shen, Z. Wanga, G. Wangb, Y. Wang, Bioresource Technology, 101, 901-906, (2010)

9. S.B Alaya., L. Haouech, H. Cherif, H. Shayeb, Desalination, 252, 172-178 (2010)

10. P. Zhang, Z. Qi, Frontiers of environmental science \& engineering in China, 1(1), 4952 (2007)

11. L. Amand, B. Carlsson, Water Research, 46, 2101-2110 (2012)

12. X. Zhou, Y. Han, X. Guo, Chemical Engineering Journal, 259, 715-723 (2015) 